\title{
ARRANJOS E REDE DE APOIO FAMILIAR DE IDOSOS QUE VIVEM EM UMA ÁREA RURAL
}

\author{
Daiane Bertuzzi ${ }^{1}$, Lisiane Girardi Manganelli Paskulin², Eliane Pinheiro de Morais ${ }^{3}$
}

\footnotetext{
${ }^{1}$ Enfermeira residente de Enfermagem em Cardiologia do Instituto de Cardiologia do Rio Grande do Sul. Rio Grande do Sul, Brasil. E-mail: daiaufrgs@yahoo.com.br

${ }^{2}$ Doutora em Ciências da Saúde. Professora Adjunto do Departamento de Assistência e Orientação Profissional da Escola de Enfermagem da Universidade Federal do Rio Grande do Sul (EEnf) da Universidade Federal do Rio Grande do Sul (UFRGS). Professora Permanente do Programa de Pós-Graduação em Enfermagem (PPGENF) da UFRGS. Rio Grande do Sul, Brasil. E-mail: paskulin@orion.ufrgs.br

${ }^{3}$ Doutora em Enfermagem Fundamental. Professora Adjunto do Departamento de Assistência e Orientação Profissional da EEnf/UFRGS. Professora Colaboradora da PPGENF. Rio Grande do Sul, Brasil. E-mail: epmorais@hotmail.com
}

RESUMO: O presente estudo identifica os arranjos familiares e descreve a rede de apoio familiar de idosos que vivem em uma área rural. Trata-se de um estudo transversal, realizado com 36 idosos, através de entrevistas no domicílio. Os resultados demonstraram um número maior de mulheres $(80,6 \%)$ entre os idosos, com boas condições de moradia e renda. O arranjo familiar mais encontrado foi o tri geracional ( $50 \%$ ), em que residem idosos, filhos e netos. Observou-se um processo de via dupla nas transferências informais entre idosos, chefes de família e outros familiares que residem com o idoso. Nas famílias em que o idoso não é o chefe familiar, os idosos recebem mais ajuda do que prestam, ocorrendo o inverso nas famílias em que o idoso é o chefe. Este estudo favorece o surgimento de ações para o idoso rural e suas famílias, que apresentam dificuldades de acesso aos serviços de saúde.

DESCRITORES: Envelhecimento. População rural. Composição familiar.

\section{ARRANGEMENTS AND SUPPORT NETWORK FAMILY FOR ELDERLY LIVING IN A RURAL AREA}

\begin{abstract}
This study identifies different family arrangements and describes the family support network for elderly who live in the Brazilian countryside. This transverse study was accomplished with thirty-six elderly through domicile interviews. Study results show a greater number of women (80.6\%) among the elderly living in good living conditions with good household income. The most common family arrangement found out was tri-generational (50\%), in which these elderly, their children, and their grandchildren all live together. The study observed a two-way process in informal transfers among these elderly, heads of the family, and other relatives living with the elderly. In families where the elderly was not the head of the household, the son usually takes up this role. In these families, the elderly receive more assistance than they provide, with the opposite occurring in families in which the elderly are the head. These results point toward the need for implementing new care actions for the rural elderly and their families which present difficulty in accessing Brazilian health care services.
\end{abstract}

DESCRIPTORS: Aging. Rural population. Family characteristics.

\section{ARREGLOS Y RED DE APOYO FAMILIAR DE ANCIANOS QUE VIVEN EN LA ZONA RURAL}

RESUMEN: Este estudio identifica los diferentes arreglos de vivienda, describe la red de apoyo familiar de los ancianos que viven en una zona rural. Es un estudo transversal, realizado com 36 ancianos, a través de entrevistas em el hogar. Los resultados mostraron un mayor número de mujeres $(80,6 \%)$ en adultos mayores, con buenas condiciones de vivienda y ingreso. La disposición de la familia más común fue trigenerational $(50 \%)$, con domicilio en las personas mayores, hijos y nietos. Hubo un proceso de doble vía de las transferencias informales entre los jefes de hogar mayores y otros familiares que viven con las personas mayores. En las familias donde los ancianos no es el jefe de familia, los ancianos reciben más ayuda que ellos proporcionan, mientras que lo contrario ocurrió en las familias donde la persona mayor es el jefe. Este estudo permite acciones para la población rural de edad avanzada y sus famílias.

DESCRIPTORES: Envejecimiento. Población rurales. Composición familiar. 


\section{INTRODUÇÃO}

O envelhecimento nas áreas rurais apresenta-se como tema emergente para as pesquisas nacionais e internacionais na área de gerontologia, em vista dos poucos estudos que abordam, especificamente, a população idosa que vive nessas áreas. A maioria destes focaliza o meio urbano para análise de pesquisa. A população do meio rural necessita ser mais estudada devido às particularidades e características significativas que apresentam e que diferem da população urbana. Destaca-se ainda que a família rural, raramente é levada em consideração na elaboração de programas públicos. ${ }^{1}$

As diferenças entre rural e urbano vão além dos aspectos quantitativos e dimensionais, como densidade populacional e distribuição geográfica, pois existem também diferenças qualitativas entre essas populações, como a diversidade dos hábitos, costumes e crenças, o acesso aos serviços de saúde, bem como o próprio processo de envelhecimento. ${ }^{2}$

Os idosos residentes em áreas rurais, além de enfrentarem os problemas de saúde do envelhecimento, têm de lidar com barreiras maiores para obter os serviços de saúde de que necessitam. ${ }^{3}$ As grandes distâncias a serem percorridas, dificuldades de transporte e baixa renda são fatores que contribuem para a dificuldade de acesso.

A população idosa rural geralmente possui altos índices de pobreza, baixo nível educacional, residências mais precárias, limitações no transporte, maiores problemas crônicos de saúde e maior dependência para as atividades básicas. ${ }^{2}$

Além disso, os idosos rurais vivenciaram e continuam vivenciando o processo de migração da população rural para os centros urbanos, principalmente da população mais jovem. Esta situação gera preocupações, dentre elas, a dificuldade de manter sucessores nas famílias para dar continuidade às atividades e a propriedade. A redução no número de membros na família rural prejudica o trabalho e, consequentemente, a renda familiar, bem como a possibilidade de cuidado mais próximo e diário com as pessoas que estão envelhecendo. Esta situação faz com que o casal idoso do meio rural, muitas vezes, fique sozinho na propriedade e enfrente diversas dificuldades que envolvem desde o trabalho cotidiano até a atenção com as questões de saúde. Observa-se que há um incentivo à vida urbana e que o meio rural está ficando cada vez mais desabitado, gerando preocupação dos idosos com o abandono do meio rural pelos jovens e a possibilidade do interior virar um "asilo". ${ }^{4}$
As consequências da migração rural urbano no Brasil são nitidamente observadas, visto que a população brasileira era principalmente rural na década de 1940, e hoje é, em sua maioria, urbana. O grau de urbanização era próximo a 30\% em 1940, já em 2000 chegou a cerca de $80 \% .^{5}$

Assim, constata-se que os idosos de áreas rurais apresentam uma grande quantidade de necessidades e problemas que devem ser investigados e solucionados. ${ }^{6}$ Torna-se necessário considerar algumas questões neste grupo de idade, levando em conta suas particularidades, para compreender o processo de envelhecimento dentro do contexto rural. ${ }^{7}$

Mudanças significativas no mundo rural, como o êxodo rural, a mecanização da agricultura e a busca de trabalho não-agrícola fora de casa pela mulher, de certa forma, abalaram as condições de possibilidade da proteção exclusivamente familiar ao idoso. ${ }^{8}$

No meio rural, a situação da família, dos idosos e de seus cuidados/cuidadores apresenta-se de forma mais complexa, pois se acrescentam dificuldades que no meio urbano não são sentidas, como, por exemplo, acesso viário nas diversas épocas do ano, falta ou escassez de serviços de saúde itinerantes, e em muitas regiões, a falta de infraestrutura como energia elétrica e meios de comunicação. ${ }^{2}$

Desta forma, diante das adversidades que os idosos rurais têm de enfrentar, percebe-se que as relações familiares e sociais, quando presentes no meio rural, apresentam um efeito protetivo para os idosos. ${ }^{2}$

Analisando o idoso no arranjo familiar, este pode residir em uma "família de idosos", onde o idoso é chefe ou cônjuge, ou em uma "família com idosos", onde o idoso mora na condição de parente do chefe (pais, sogros e tios do chefe). ${ }^{9}$ Esta classificação torna-se interessante, pois a partir dela pode-se observar a dependência do idoso em relação aos demais membros da família. A família no meio rural presta um grande serviço na assistência aos velhos e aos incapazes. ${ }^{1}$ Esse cuidado é praticado comumente nas cidades interioranas com características rurais. O cuidado ao idoso acaba sendo uma tarefa solitária, não existe organização nas famílias, quem assume a responsabilidade ou são as mulheres ou o filho que ficou com os bens de moradia dos pais. ${ }^{4}$

Frente ao envelhecimento crescente tanto em áreas rurais como urbanas, surgiu o interesse de conhecer como as famílias rurais estavam se organizando perante este fenômeno, bem como os tipos de auxílio recebidos e prestados pelos idosos de uma área rural. Desta forma, realizou-se um estudo no município de Nova Bassano, que se localiza no nordeste do Rio Grande do Sul, na 
região serrana, a $190 \mathrm{~km}$ da capital. A pesquisa foi realizada na zona rural deste, denominada Linha Senador Ramiro. Nesta localidade os habitantes possuem práticas e costumes de origem italiana, fortemente arraigada, como o dialeto e a gastronomia, principalmente entre as pessoas mais velhas.

Este estudo mostra-se relevante, uma vez que o envelhecimento é uma realidade também das áreas rurais, onde a concentração de idosos acentua-se pela diminuição da população jovem no campo. Além do mais, pouco se conhece sobre as redes de apoio para a família rural, especialmente relacionado ao processo de envelhecimento.

O presente artigo tem por objetivo identificar os diferentes arranjos familiares e conhecer a rede de apoio familiar dos idosos que vivem em uma área rural de Nova Bassano-RS, bem como caracterizar as condições socioeconômicas e demográficas desses idosos. Acredita-se que com as informações obtidas, seja possível realizar programas de apoio e propor novas ações para atender e acompanhar o idoso rural e seus familiares nas suas particularidades. Além disso, contribuirá para os profissionais da enfermagem e da saúde no sentido de atentarem a esta população, a qual apresenta dificuldades de acesso aos serviços de saúde, dentre outras adversidades.

\section{MÉTODOS}

A pesquisa caracteriza-se por ser um estudo com abordagem quantitativa, com delineamento descritivo e transversal. Nova Bassano possui uma população de 8.749 habitantes, sendo que 1.191 pessoas (12\%) têm 60 anos ou mais ${ }^{10}$ e na Linha Senador Ramiro residem 94 famílias rurais. Das 94 famílias, aproximadamente 43 delas possuem um ou mais de seus membros com 60 anos ou mais. Sendo assim, 43 famílias foi o número inicial da coleta dos dados, sendo que, por opção das pesquisadoras, somente seria entrevistado um idoso por família. O idoso entrevistado foi o encontrado na residência no momento da coleta dos dados. Quando havia mais de um idoso, então, era realizado um sorteio. As informações sobre as famílias que tinham idosos foram obtidas através de um informante chave da região. Foram entrevistadas 36 famílias (36 idosos). Das 43 famílias, cinco não foram encontradas após três tentativas e apenas uma família não aceitou participar do estudo.

Os dados foram coletados em entrevistas individuais no domicílio das famílias rurais, através de um instrumento baseado em seções do Projeto
SABE (Projeto Saúde, Bem-Estar e Envelhecimento $)^{11}$, no período de julho a dezembro de 2008 . O instrumento contemplou a seção A (informações pessoais) e a seção D (rede de apoio familiar e social) do Projeto SABE, sendo realizadas adequações ao contexto rural. A escolha do instrumento de coleta de dados deu-se por ser de fácil compreensão e aplicabilidade. Através de questões estruturadas e pré-codificadas, estabeleceram-se as características sócio-demográficas (sexo, idade, estado conjugal, escolaridade, religião, trabalho atual, aposentadoria, renda) e a rede de apoio familiar do idoso (familiares e não familiares que vivem e não vivem com o idoso, ajuda prestada ao idoso pela família e fornecida por ele referente a cada membro citado, atividades de lazer do idoso). As adequações foram relativas ao ambiente rural para este estudo, como por exemplo, a introdução do item sindicato rural nos serviços de saúde e afazeres domésticos e na agricultura, na questão sobre trabalho. O instrumento citado foi construído para aplicação em áreas urbanas, onde muitas das questões não se aplicam para população que vive em áreas rurais.

Foi realizado teste piloto com três idosos residentes na mesma região, a fim de testar o instrumento quanto ao tempo despendido para tal, verificar a compreensão das questões e familiarizar a entrevistadora com o mesmo.

Os dados foram gerenciados através do banco de dados software Statiscal Package for the Social Sciences (SPSS) for Windows, versão 12.0. Utilizou-se estatística descritiva (frequência simples e relativa).

Todos os participantes assinaram o Termo de Consentimento Livre e Esclarecido em duas vias. O projeto foi aprovado pelo Comitê de Ética da Universidade Federal do Rio Grande do Sul (processo $n^{\circ} 2007933$ ).

\section{RESULTADOS}

Dos 36 idosos que participaram do estudo, 29 $(80,6 \%)$ eram mulheres e sete $(19,4 \%)$ homens. Em relação à faixa etária, a idade mínima dos idosos foi 60 e a máxima 86 , com predominância dos idosos de 60 a 69 anos (50\%).

Quanto ao estado conjugal, mais da metade, $61,1 \%$, dos idosos eram casados, 33,3\% estavam sem companheiro atual e 5,6\% nunca tinham casado. Considerando a relação entre sexo e estado conjugal, observa-se que $100 \%$ dos homens eram casados, enquanto $51,7 \%$ das mulheres eram casadas e $41,4 \%$ viúvas. 
Observou-se um baixo nível de escolaridade entre os idosos, uma vez que, $75 \%$ deles não chegaram a completar cinco anos de estudo. A taxa de analfabetismo foi maior entre as mulheres (10,3\%) em relação aos homens. Quanto à religiosidade, $100 \%$ dos sujeitos referiram ter alguma religião; destes, $97,2 \%$ afirmaram-se católicos e 2,8\% evangélicos.

Todos os idosos recebiam aposentadoria rural: $88,9 \%$ por idade; $8,3 \%$ por tempo de serviço e $2,8 \%$ por invalidez. Entretanto, a maioria continuava trabalhando $(86,1 \%)$. Quanto ao valor do benefício, 91,7\% recebiam um salário mínimo, sendo que $66,6 \%$ dos idosos possuíam outra fonte de renda, além da aposentadoria. Nos últimos seis meses, os idosos gastaram a maior parte de seu dinheiro com alimentação e medicamentos (36,1\%), com alimentação $(33,3 \%)$ e com medicamentos (25\%).

A renda familiar mensal mais encontrada nas famílias dos idosos correspondeu ser maior que quatro salários mínimos* $(63,9 \%)$, sendo que o número de indivíduos que viviam desta renda era de cinco pessoas $(27,8 \%)$. Verificou-se durante as entrevistas que esta renda sofre variações durante o ano, a qual esta relacionada com a venda dos insumos agrícolas que as famílias produzem.

A tabela 1 refere-se às informações socioeconômicas e demográficas dos idosos de Nova Bassano-RS que vivem em uma área rural.

Tabela 1 - Caracterização socioeconômica e demográfica, segundo sexo dos idosos da Linha Senador Ramiro. Nova Bassano-RS, 2008

\begin{tabular}{|c|c|c|c|c|c|c|}
\hline \multirow{3}{*}{ Variável } & \multicolumn{4}{|c|}{ Sexo } & \multirow{2}{*}{\multicolumn{2}{|c|}{ Total }} \\
\hline & \multicolumn{2}{|c|}{ Homem } & \multicolumn{2}{|c|}{ Mulher } & & \\
\hline & $\mathbf{n}$ & $\%$ & $\mathbf{n}$ & $\%$ & $\mathbf{n}$ & $\%$ \\
\hline \multicolumn{7}{|l|}{ Idade } \\
\hline 60 a 69 anos & 5 & 71,4 & 13 & 44,9 & 18 & 50,0 \\
\hline 70 a 79 anos & 2 & 28,6 & 11 & 37,9 & 13 & 36,1 \\
\hline 80 anos ou mais & - & - & 5 & 17,2 & 5 & 13,9 \\
\hline \multicolumn{7}{|l|}{ Estado conjugal } \\
\hline Casado ou união estável & 7 & 100,0 & 15 & 51,7 & 22 & 61,1 \\
\hline Sem companheiro atual & - & - & 12 & 41,4 & 12 & 33,3 \\
\hline Nunca casou & - & - & 2 & 6,9 & 2 & 5,6 \\
\hline \multicolumn{7}{|l|}{ Tempo de estudo } \\
\hline Sem escolaridade & - & - & 3 & 10,3 & 3 & 8,3 \\
\hline 1 a 4 anos de estudo & 5 & 71,4 & 22 & 75,9 & 27 & 75,0 \\
\hline 5 a 8 anos de estudo & 2 & 28,6 & 2 & 6,9 & 4 & 11,1 \\
\hline Mais de 8 anos de estudo & - & 0,0 & 2 & 6,9 & 2 & 5,6 \\
\hline \multicolumn{7}{|l|}{ Religião } \\
\hline Católica & 7 & 100,0 & 28 & 96,6 & 35 & 97,2 \\
\hline Evangélica & - & 0,0 & 1 & 3,4 & 1 & 2,8 \\
\hline \multicolumn{7}{|l|}{ Forma de aposentadoria } \\
\hline Por idade & 5 & 71,4 & 27 & 93,1 & 32 & 88,9 \\
\hline Por tempo de serviço & 1 & 14,3 & 2 & 6,9 & 3 & 8,3 \\
\hline Invalidez & 1 & 14,3 & - & - & 1 & 2,8 \\
\hline \multicolumn{7}{|l|}{ Valor da aposentadoria } \\
\hline 1 salário mínimo & 6 & 85,7 & 27 & 93,1 & 33 & 91,7 \\
\hline 2 salários mínimos & 1 & 14,3 & 2 & 6,9 & 3 & 8,3 \\
\hline \multicolumn{7}{|c|}{ Renda familiar mensal (salário mínimo*) } \\
\hline Menos de 2 & 1 & 14,3 & 4 & 13,8 & 5 & 13,9 \\
\hline 2 a 4 & 1 & 14,3 & 7 & 24,1 & 8 & 22,2 \\
\hline Mais que 4 & 5 & 71,4 & 18 & 62,1 & 23 & 63,9 \\
\hline \multicolumn{7}{|c|}{ Formas de gastos nos últimos 6 meses } \\
\hline Alimentação e medicamentos & 1 & 14,3 & 12 & 41,4 & 13 & 36,1 \\
\hline Alimentação & 4 & 57,1 & 8 & 27,6 & 12 & 33,3 \\
\hline Medicamentos & 2 & 28,6 & 7 & 24,1 & 9 & 25,0 \\
\hline Moradia & - & - & 1 & 3,4 & 1 & 2,8 \\
\hline Outros & - & - & 1 & 3,4 & 1 & 2,8 \\
\hline \multicolumn{7}{|l|}{ Trabalha atualmente } \\
\hline Sim & 6 & 85,7 & 25 & 86,2 & 31 & 86,1 \\
\hline Não & 1 & 14,3 & 4 & 13,8 & 5 & 13,9 \\
\hline Total & 7 & 100,0 & 29 & 100,0 & 36 & 100,0 \\
\hline
\end{tabular}

* Salário mínimo vigente $\mathrm{R} \$ 415,00$ (set. 2008)

* Salário mínimo R \$ 415,00. 
Dos 36 idosos entrevistados na área rural de Nova Bassano-RS, mais da metade, 55,6\%, residiam em domicílios com quatro ou cinco pessoas. Somente $8,3 \%$ dos idosos viviam sozinhos, mostrando que quase a totalidade vivia acompanhada $(91,7 \%)$. A maioria dos idosos possuía mais de seis filhos $(30,6 \%)$.

Tabela 2 - Classificação dos arranjos familiares dos idosos da Linha Senador Ramiro. Nova Bassano- RS, 2008

\begin{tabular}{lrr}
\hline Arranjos familiares dos idosos & $\mathbf{n}$ & \multicolumn{1}{c}{$\%$} \\
\hline A - vive sozinho & 3 & 8,3 \\
B - vive somente com o cônjuge & 5 & 13,9 \\
C - cônjuge+filho/cônjuge+filho+genro ou nora & 7 & 19,4 \\
D - arranjos tri geracionais (filho e neto) & 18 & 50,1 \\
E - arranjos intra geracionais (irmãos, pais) & 3 & 8,3 \\
\hline Total & $\mathbf{3 6}$ & $\mathbf{1 0 0 , 0}$ \\
\hline
\end{tabular}

No presente estudo, encontramos diferentes tipos de arranjos familiares, conforme tabela 2. Nas famílias entrevistadas predominou os arranjos tri geracionais (grupo D) em que o idoso reside com os filhos e netos (50,1\%); em segundo $(19,4 \%)$, os arranjos em que o idoso vive com o cônjuge, filhos ou nora (grupo C); em terceiro $(13,9 \%)$, os arranjos em que o idoso vive somente com o cônjuge (grupo B); e em quarto (8,3\%), os arranjos em que o idoso vive sozinho (grupo A), e intra geracionais, com pais e irmãos (grupo E). Os arranjos em que residem avós e netos, sem os filhos, e o idoso com não-familiares não apareceu entre as famílias dos idosos entrevistados.

Com relação a ser chefe da família, o estudo apontou que em metade das famílias o chefe familiar era o filho do idoso, 27,8\% o próprio idoso, $13,9 \%$ o cônjuge, 5,6 \% outras pessoas da família, como irmãos e sobrinhos, e 2,7\%, o genro.

Analisando o arranjo familiar, tendo como referência o idoso, observou-se que mais da metade dos idosos, 58,3\%, residem em famílias "com idosos", mas um número bem expressivo, 41,7\% reside em famílias "de idosos".

Quanto à rede de apoio familiar (Tabela 3), a ajuda oferecida ao idoso e prestada por ele advinha, na maioria das vezes, das pessoas com quem ele residia e dos filhos.

Tabela 3 - Proporção de idosos que recebeu e prestou auxílio ao chefe familiar e aos demais familiares segundo os tipos de auxílio, da Linha Senador Ramiro. Nova Bassano-RS, 2008

\begin{tabular}{|c|c|c|c|c|}
\hline \multirow[t]{2}{*}{ Tipos de auxílio } & \multicolumn{2}{|c|}{$\begin{array}{c}\text { Auxílio recebido pelo idoso } \\
\text { do chefe familiar }\end{array}$} & \multicolumn{2}{|c|}{$\begin{array}{l}\text { Auxílio prestado pelo } \\
\text { idoso ao chefe familiar }\end{array}$} \\
\hline & n & $\%$ & $\mathbf{n}$ & $\%$ \\
\hline \multicolumn{5}{|l|}{ Famílias cujo chefe não é o idoso } \\
\hline Dinheiro & 16 & 61,5 & 13 & 50,0 \\
\hline Transporte, ajuda nas tarefas de casa, agrícolas & 26 & 100 & 22 & 84,6 \\
\hline Comida, roupa, utensílios & 18 & 69,2 & 17 & 65,4 \\
\hline Lazer, diversão & 4 & 15,4 & - & - \\
\hline Companhia & 22 & 84,6 & - & - \\
\hline Cuidando de crianças & - & - & 10 & 38,5 \\
\hline \multirow[t]{2}{*}{ Total de famílias cujo chefe não é o idoso } & \multicolumn{2}{|c|}{26} & & \\
\hline & \multicolumn{2}{|c|}{$\begin{array}{l}\text { Auxílio recebido pelo idoso } \\
\text { dos demais familiares }\end{array}$} & \multicolumn{2}{|c|}{$\begin{array}{c}\text { Auxílio prestado pelo } \\
\text { idoso aos demais familiares }\end{array}$} \\
\hline \multicolumn{5}{|l|}{ Famílias cujo chefe é o idoso } \\
\hline Dinheiro & 1 & 10,0 & 7 & 70,0 \\
\hline Transporte, ajuda nas tarefas de casa, agrícolas & 4 & 40,0 & 7 & 70,0 \\
\hline Comida, roupa, utensílios & 1 & 10,0 & 7 & 70,0 \\
\hline Lazer, diversão & 1 & 10,0 & - & - \\
\hline Companhia & 4 & 40,0 & - & - \\
\hline Cuidando de crianças & - & - & - & - \\
\hline Total de famílias cujo chefe é o idoso & 1 & & & \\
\hline
\end{tabular}


Nas famílias em que o idoso não era o chefe, os tipos de auxílio mais frequentes foram: auxílio com transporte, nas tarefas de casa e agrícolas (100\% recebiam e $84,6 \%$ prestavam); roupas, comida, utensílios (69,2\% recebiam e $65,4 \%$ prestavam); e com dinheiro (61,5\% recebiam e $50 \%$ prestavam). Também os idosos recebiam ajuda na forma de companhia $(84,6 \%)$, com lazer e diversão $(15,4 \%)$ e prestavam ajuda cuidando das crianças $(38,5 \%)$.

Nas famílias em que o idoso era o chefe, os tipos de ajuda que ele recebia e oferecia a outros familiares também se baseavam em transporte, nas tarefas de casa e agrícolas (40\% recebia e 70\% oferecia), com roupas, comida, utensílios para casa ( $10 \%$ recebia e $70 \%$ oferecia), com dinheiro $(10 \%$ recebia e $70 \%$ oferecia), na forma de companhia (40\% recebia), com lazer e diversão (10\% recebia) e a ajuda cuidando de crianças não apareceu.

Em relação à interação social dos idosos da linha Senador Ramiro, Nova Bassano-RS, observou-se que a atividade que os idosos mais participavam era as festas da comunidade $(80,6 \%)$. Uma grande parte dos idosos (52,8\%) participava, assiduamente, do grupo de idosos, mais conhecido como grupo da "Terceira Idade".

\section{DISCUSSÃO}

Neste estudo, observa-se que as mulheres predominam sobre os homens, confirmando a feminização do envelhecimento, encontrada em outros estudos com idosos que vivem tanto no meio rural quanto no meio urbano. ${ }^{2,12-13} \mathrm{~A}$ feminização do envelhecimento é um fenômeno que acorre mundialmente e de forma acelerada no Brasil. Contudo, existem estudos que afirmam a predominância masculina em áreas rurais devido a maior participação das mulheres no fluxo migratório rural urbano. ${ }^{14}$

A predominância dos idosos na faixa etária de 60 a 69 anos concorda com a distribuição etária da população idosa do RS em 1997. ${ }^{13}$ Assim, observa-se que a maioria dos idosos entrevistados podem ser classificados como "idosos jovens", os quais continuam trabalhando e gerenciando a renda familiar.

Há maior proporção de idosos casados do que idosas casadas e significativo percentual de mulheres viúvas, dado encontrado no censo demográfico de 2000, em que as mulheres viúvas constituíam $41 \%$ das mulheres idosas e $80 \%$ dos homens estavam em algum tipo de união conjugal. ${ }^{12} \mathrm{No}$ Brasil, a mulher apresenta maior incidência de viuvez, pois tem uma expectativa de vida maior que o cônjuge, e os homens apresentam maior facilidade de recasamento do que as mulheres. ${ }^{11-12,14}$

$\mathrm{O}$ analfabetismo, aparecendo com taxas mais elevadas entre as mulheres, também é observado no estudo. ${ }^{2}$ Uma possível explicação pelo fato dos homens serem mais alfabetizados, é que até os anos de 1960, eles tinham mais acesso à escola do que as mulheres. ${ }^{12}$

Quanto à religiosidade, a maioria dos idosos faz devoção à Igreja Católica, devido à forte cultura presente nos descendentes italianos, corroborando com outros estudos realizados em comunidades rurais. ${ }^{15-16}$

A aposentadoria rural, para o trabalhador do campo, iniciou a partir da Constituição de 1988. Vários estudos apontam os efeitos benéficos da aposentadoria para o idoso que vive no meio rural. ${ }^{2,4,17}$

Entretanto, observa-se neste estudo que a maioria dos idosos continua trabalhando ativamente, apesar de receberem a aposentadoria rural. Isso demonstra que a aposentadoria no caso rural não representa o fim do trabalho, mas sim um acréscimo da renda, que pode contribuir na melhora da qualidade de vida e aproveito da vida.

Para a população rural, o trabalho é um valor fundamental e está associado a ser fonte de renovação, porém este pode representar uma ameaça à saúde física, principalmente nas pessoas mais idosas, pois ao longo da vida, os mesmos foram expostos a diversas situações de riscos como o uso de agrotóxicos, de inúmeras máquinas e equipamentos para os quais, muitas vezes não tem preparo e conhecimento de manejo e ainda, estão sujeitos as intempéries do clima e ao pesado trabalho na agropecuária com longas jornadas. ${ }^{1}$ Assim sendo, o trabalho rural apresenta-se como uma situação limite para os idosos, uma vez que, ao mesmo tempo é um indicador de ter saúde e um fator de adoecimento. ${ }^{15}$

Outra situação ligada ao trabalho no meio rural, é que este, em muitas culturas, se caracteriza por uma divisão de tarefas entre homens e mulheres. Alguns estudo ${ }^{1,15}$ apontam que esta divisão gera sobrecarga para as mulheres, pois além dos afazeres domésticos que realizam normalmente sozinhas, muitas vezes dividem com os homens o trabalho na lavoura e no cuidado dos animais. ${ }^{14}$

Os setores de alimentação e saúde foram as áreas que mais absorveram a renda dos aposentados, corroborando com estudo já realizado. ${ }^{17}$ A renda encontrada nos idosos do meio rural de 
Nova Bassano (Norte do RS) é superior a que foi encontrada nos idosos do meio rural de Arambaré (Sul do RS) em 2005, que se apresenta entre um a menos de dois salários mínimos. ${ }^{16}$

A classificação dos arranjos familiares citados no presente estudo leva em consideração, principalmente, a presença de filhos ou cônjuges no domicílio do idoso, pelo fato de serem eles que, com maior frequência, participam das transferências de apoio informal com os idosos. ${ }^{18} \mathrm{O}$ arranjo tri geracional também foi superior aos demais em outros estudos, nos países de Cuba e Chile e no município de São Paulo. Os arranjos tri geracionais (arranjo D) parecem auxiliar em maior proporção que os bi geracionais (arranjo C). Os idosos que moram sozinhos (arranjo A) são os que menos contam com auxílio. ${ }^{19}$

O espaço doméstico rural facilita a convivência entre gerações e aproxima as pessoas. Os filhos crescem, casam, constituem famílias e ficam morando nas proximidades da casa dos pais ou juntos deles. ${ }^{4}$ Isso nem sempre é possível no meio urbano. A família rural presta um grande serviço na assistência ao velho e aos incapazes. Desta forma, constata-se que a rede de apoio familiar do meio rural se organiza diferente da do meio urbano. As famílias rurais vivem mais em arranjos tri geracionais, o que facilita o cuidado diário, já que as pessoas dividem o mesmo espaço de convivência e trabalho. ${ }^{1}$

A corresidência entre idosos e filhos tem sido uma prática generalizada nos arranjos domiciliares. Algumas vezes, os beneficiários são os idosos, e em outras, os filhos e netos. Analisando o arranjo familiar, tendo como referência o idoso, aparecem duas composições familiares distintas: "famílias de idosos", onde o idoso é chefe ou cônjuge e "famílias com idosos", onde o idoso mora na condição de parente do chefe (pais, sogros e tios do chefe). ${ }^{9}$

O presente estudo aponta que em metade das famílias dos idosos entrevistados o chefe familiar é representado pelo filho do idoso, contrapondo os dados brasileiros, em que $86 \%$ das famílias onde residem idosos estes são os chefes. Normalmente, os idosos residindo nas famílias de idosos são mais jovens e apresentam condições econômicas melhores do que os das famílias com idosos. Em geral, os homens permanecem como chefes da família até o fim da vida, mas as mulheres quando sozinhas (viúvas, separadas) moram com os filhos. ${ }^{9}$

A partir dos resultados, constata-se que os idosos que são chefes de família prestam mais ajuda do que recebem principalmente na forma de dinheiro, em transporte, no dia-a-dia nas tarefas agrícolas, com comida e roupas. Além disso, podemos inferir que esses idosos não prestam ajuda no cuidado com crianças, pois os filhos com quem residem não são casados ou não tem filhos. A corresidência não se dá apenas por necessidade do idoso, mas também da população mais jovem, que está permanecendo economicamente dependente de seus pais por períodos mais longos devido à instabilidade do mercado de trabalho. ${ }^{9}$

Já nas famílias em que o idoso não é o chefe, sendo este o filho, na maioria dos casos, os idosos recebem mais ajuda do que prestam, aparecendo com mais frequência o auxílio com transporte, nas tarefas de casa e agrícolas, com companhia, roupa e comida. Neste caso, em que o idoso não é o chefe da família, observamos um processo maior de via dupla nas transferências de apoio informais, em que os idosos recebem e fornecem apoio com bastante frequência, concordando com o que foi encontrado em São Paulo no projeto SABE. ${ }^{18}$

Em estudo realizado com idosos que viviam sozinhos em comparação com idosos que viviam com a família, observou-se maiores índices de autoestima, saúde física, apoio familiar e comportamentos preventivos de saúde, como nutrição e exercício físico, entre os idosos que viviam com a família. ${ }^{20}$

A família dos idosos que vivem no meio rural é a principal fonte de recurso e apoio, uma vez que os serviços sociais de saúde praticamente inexistem neste meio. Portanto, é possível dizer que a família representa um fator de proteção para o envelhecimento no meio rural. ${ }^{2} \mathrm{O}$ meio rural traz presente a troca de favores e "a ajuda", elementos constantes entre as famílias rurais. ${ }^{4}$

As festas realizadas nas comunidades rurais são organizadas por casais festeiros, assim como o encontrado em outros estudos. As mulheres são encarregadas de preparar os doces, pães, cucas, que serão vendidos na festa e os homens pela organização das mesas, da carne, do churrasco e das bebidas. ${ }^{15}$

O grupo da "Terceira Idade" da Linha Senador Ramiro é formado por mais de 80 idosos e os encontros acontecem quinzenalmente. As atividades do grupo se baseiam em bailes, passeios para outras cidades, jantares e churrascos. O grupo permite o encontro dos idosos para momentos de lazer, descontração e informação, ajudando a construir uma nova identidade, buscando formas diferentes de se cuidar, de participar e de viver esta etapa da vida. ${ }^{4}$ 
A aposentadoria rural auxilia o idoso a participar dos grupos de idade, pois oferece autonomia e recursos para o lazer. É a partir da aposentadoria que muitos idosos do meio rural, normalmente as mulheres, redefinem suas vidas. ${ }^{21}$

\section{CONCLUSÕES}

Este estudo contribui com as pesquisas sobre o envelhecimento no meio rural, que está aumentando rapidamente, mas que apresenta carência de estudos acerca do tema. O estudo identificou os arranjos familiares e descreveu a rede de apoio familiar de idosos que vivem em uma área rural. Também foram caracterizadas as condições socioeconômicas e demográficas dos idosos entrevistados.

Observou-se um processo de via dupla no auxílio prestado e recebido pelo idoso ao chefe de família e a outros familiares. Nas famílias em que o idoso não é o chefe, os idosos recebem mais ajuda do que prestam, principalmente, na forma de companhia, com transporte, nas tarefas de casa e agrícolas. Já nos idosos chefes de família, estes mais prestam do que recebem ajuda.

$\mathrm{O}$ arranjo tri geracional, em que vivem idosos, filhos e netos, foi o mais encontrado entre as famílias dos idosos da Linha Senador Ramiro, sendo que a mulher idosa reside mais com esse tipo de arranjo familiar que o homem. Constata-se que o arranjo tri geracional facilita o cuidado com os idosos, exercendo um fator de proteção.

Os profissionais de enfermagem, que atuam junto a esta população, podem criar estratégias e ações mais específicas para o meio rural, promovendo a saúde e aumentando as redes de apoio formal e informal para o idoso que vive no campo.

As redes de apoio sociais são importantes e tornam-se mais eficientes quando realizadas em paralelo com as redes de apoio familiar. A Igreja Católica para esta população estudada pode ser uma dessas redes de apoio social, onde se mostra como um efeito protetivo e de apoio aos idosos rurais, os quais são muito devotos.

Podemos concluir que as limitações deste estudo podem ser vistas como as encontradas pela população que vive em áreas rurais, ou seja, grandes distâncias do centro urbano, o transporte deficiente, dentre outros. Entende-se que estudos direcionados para esta população são cada vez mais necessários, uma vez que o envelhecimento está sendo sentido para além dos "muros" das cidades.

\section{REFERENCIAS}

1. Schwartz E. O viver, o adoecer e o cuidar das famílias de uma comunidade rural do extremo sul do Brasil: uma perspectiva ecológica [tese]. Florianópolis (SC): Universidade Federal de Santa Catarina, Programa de Pós- Graduação em Enfermagem; 2002.

2. Morais EP. Rodrigues RAP, Gerhardt TE. Os idosos mais velhos no meio rural: realidade de vida e saúde de uma população do interior gaúcho. Texto Contexto Enferm. 2008 Abr-Jun; 17(2):374-83.

3. Travassos C, Viacava F. Acesso e uso de serviços de saúde em idosos residentes em áreas rurais, Brasil, 1998 e 2003. Cad Saude Publica. 2007 Out; 23(10):2490-502.

4. Missio M, Portella MR. Atenção aos idosos rurais no contexto da família: um desafio para a equipe do Programa Saúde da Família. Boletim da Saúde. 2003 Jul-Dez; 17(2):25-36.

5. Beltrão KI, Pinheiro SS, Peyneau FPL, Mendonça JL. O. A constituição de 1988 e o acesso da população rural brasileira à seguridade social. In: Camarano AA. Os novos idosos brasileiros muito além dos 60 ? Rio de Janeiro: IPEA, 2004. p. 321-352.

6. Montes JFG, Borrero CLC. Envejecimiento rural: el anciano em lãs zonas cafeteras colombianas. Cuad Investigación. 2003; 3:27-34.

7. Treviño-Siller S, Pelcastre-Villafuerte B, MárquezSerrano M. Experiências de envejecimiento en el México rural. Salud Publica Mex. 2006; 48(1):30-8.

8. Delgado GC, Cardoso JR JC. O idoso e a previdência rural no Brasil: a experiência recente da universalização. In: Camarano, AA. Os novos idosos brasileiros muito além dos 60 ? Rio de Janeiro: IPEA, 2004. p. 293-320.

9. Camarano AA, El Ghaouri SK. Famílias com idosos: ninhos vazios? Rio de Janeiro: Instituto de Pesquisa Econômica Aplicada, 2003. (Textos para discussão, $\mathrm{n}^{\circ}$ 950).

10. Ministério da Saúde (Brasil). Instituto Brasileiro de Geografia e Estatística. Contagem da População 2007 [acesso 2008 Jun 21]. Disponível em: http:/ / censos2007.ibge.gov.br/

11. Lebrão ML, Duarte YAO. Projeto SABE no município de São Paulo: uma abordagem inicial. Brasília, DF: Organização Pan-americana de Saúde, 2003.

12. Ministério da Saúde (Brasil). Instituto Brasileiro de Geografia e Estatística. Perfil dos idosos responsáveis pelos domicílios no Brasil 2000. Rio de Janeiro: IBGE, 2002.

13. Rio Grande do Sul. Conselho Estadual do Idoso. Os idosos do Rio Grande do Sul: estudo multidimensional de suas condições de vida: relatório de pesquisa. Porto Alegre (RS): Conselho Estadual do Idoso; 1997.

14. Camarano AA, Kanso S, Mello JL, Pasinato MT. Famílias: espaço de compartilhamento de recursos 
e vulnerabilidades. In: Camarano AA. Os novos idosos brasileiros muito além dos 60 ? Rio de Janeiro, IPEA, 2004. p. 137-168.

15. Denardin Budo MLD, Gonzales RMB, Beck CLC. Saúde e trabalho: uma correlação de conceitos na perspectiva de uma população rural e de Christophe Dejours. Rev Gaucha Enferm. 2003 Abr; 24(1):43-52.

16. Silva JLA. O idoso do município de Arambaré-RS: um contexto rural de envelhecimento [dissertação]. Porto Alegre (RS): Universidade Federal do Rio Grande do Sul. Escola de Enfermagem; 2005.

17. Augusto HA, Ribeiro EM. O idoso rural e os efeitos das aposentadorias rurais nos domicílios e no comércio local: o caso de Medina, nordeste de Minas. In: Anais do XV Encontro Nacional de Estudos Populacionais, 2006 Set 18-22; Caxambú, Brasil. Caxambú (MG): ABEP; 2006.
18. Saad PM. Arranjos domiciliares e transferências de apoio informal. In: Lebrão ML, Duarte YAO. SABE (saúde, bem-estar e envelhecimento) - O Projeto SABE no município de São Paulo: uma abordagem inicial. Brasília: OPS, 2003. p. 203-24.

19. Duarte YAO, Lebrão ML, Lima FD. Contribuição dos arranjos domiciliares para o suprimento de demandas assistenciais dos idosos com comprometimento funcional em São Paulo, Brasil. Rev Panam Salud Publica. 2005; 17(5/6):370-8.

20. Sok SR, Yun EK. A comparison of physical health status, self-esteem, family support and healthpromoting behaviours between aged living alone and living with family in Korea. J Clin Nurs. 2011; 20(11/12):1606-12.

21. Woortmann K, Woortmann E. Velhos camponeses. Humanidades, Terceira Idade. 1999 Out; 46:132-40. 